ISSN 0258-7122

Bangladesh J. Agril. Res. 36(2) : 197-203, June 2011

\title{
IMPACT ASSESSMENT OF PHEROMONE TRAPS TO MANAGE FRUIT FLY ON SWEET GOURD CULTIVATION
}

\author{
ATANU RAKSHIT ${ }^{1}$, A. N. M. REZAUL KARIM ${ }^{2}$, TATJANA HRISTOVSKA ${ }^{3}$ \\ AND GEORGE W. NORTON ${ }^{4}$
}

\begin{abstract}
This paper assessed the economic benefits of managing fruit flies infecting sweet gourd using pheromones. In this study, a pheromone called Cuelure imported by the Bangladesh Agricultural Research Council (BARC) was used for suppressing fruit fly infesting sweet gourd. Analysis of the potential benefits of farmers adopting the Cuelure technology projects that benefits over 15 years range from 187 million Taka or $\$ 2.7$ million to 428 million Taka or \$6.3 million, depending on assumptions. The projected rate of return on the BARI investment in pheromone research ranges from to 140 to 165 percent. The size of these returns implies that pheromone research at BARI has a high economic return and that Bangladesh benefits significantly as Cuelure becomes more widely available to farmers.
\end{abstract}

Keywords: 1PM, pheromone, sweet gourd, economic impact assessment.

\section{Introduction}

Cucurbits occupy 66 percent of the land under vegetable production in Bangladesh and contribute 11 percent of total vegetable production in the country (1PM CRSP, 2004). Cucurbits include crops, such as cucumber, squash, watermelon, pumpkin (sweet gourd), and muskmelon. Fruit fly, Bactrocera cucurbitae Coquillet, is a major pest causing yield loss in cucurbits, and infests all 15 kinds of cucurbit vegetables grown in Bangladesh. A major constraint improved cucurbit production is high rate of fruit fly infestation. Fruit flies reduce yield as well as the quality fruit (1PM CRSP, 2004). One of the primary cucurbit crops attacked by fruit fly is sweet gourd. Bangladesh produced 103 thousand tons of sweet gourd in the winter season and 77 thousand tons in the summer season of 2006-2007 (BBS, 2010).

Scientists at the Bangladesh Agricultural Research Institute (BARI) in collaboration with the USAID funded Integrated Pest Management Collaborative

${ }^{1}$ Graduate Research Assistant-PhD Candidate, Agricultural \& Applied Economics Department, Virginia Tech, Blacksburg, VA, USA, ${ }^{2}$ Site Coordinator, IPM CRSP, HRC, BARI, Gazipur, Bangladesh, ${ }^{3}$ Research Assistant, Agricultural \& Applied Economics Department, Virginia Tech. Blacksburg, VA, USA, ${ }^{4}$ Professor, Agricultural \& Applied Economics Department. Virginia Tech, Blacksburg, VA, USA. 
Research Support Program (1PM CRSP) conducted field experiments which indicate that bait trapping for fruit fly control in cucurbits with a synthetic pheromone called Cuelure and mashed sweet gourd (MSG) is highly effective. Fruit fly infestation was reduced by 53 to 73 percent and yields were raised 1.4 to 2.3 times using the traps (1PM CRSP Annual Highlights, 2002-2003). Farmers in Bangladesh have shown strong interest in adopting the pheromone lure for monitoring of peak pest infestation periods as well as for mass trapping. They are able to minimize fruit fly damage, and reduce the use of toxic insecticides.

Because of its effectiveness in controlling fruit fly and higher economic returns due to higher yields, approximately 90 percent of farmers in one of the main vegetable growing areas in Jessore district of Bangladesh adopted Cuelure pheromone bait traps when they were made available to them by BARI for their bitter gourd crop in 2003 summer season. In the subsequent years, bait trapping with Cuelure pheromone has become popular among farmers who grow other cucurbit crops as well in each of the 1PM CRSP pilot demonstration sites in Gazipur, Comilla, Narsingdi, Chittagong, Bogra and Pabna districts. Recognizing the benefits of using pheromone bait trapping for fruit fly control, such as higher crop yields, increased income, and reduced insecticide use, the national Pesticide Technical Advisory Committee (PTAC) recommended to the Ministry of Agriculture (MoA) of the Government of Bangladesh that import and use of the pheromone be allowed in the country. In 2007, the Ministry of Agriculture gave special permission to BARC to make the pheromone available for its use in and around the pilot demonstration areas. A small amount of Cuelure pheromone was purchased by BARC to be distributed to farmers without mark-up over its purchase price. A small private firm (Safe Agriculture Bangladesh Ltd.) is now also importing "Cuelure" through a special permission from BARC and is selling it to cucurbit farmers for 50 Taka (US\$0.80) (pheromone lure including the plastic trap).

One of the decision making criterion that the Bangladesh government faces with regard to allowing the registration of pheromones for import and manufacture and its economic impact on the agricultural sector in general and individual farmers specifically. Environmental effects are more difficult to assess, but are also an important consideration for policy makers. The objective of this study is to conduct an economic assessment of the total benefits to producers and consumers if farmers widely adopt the pheromone technology when producing sweet gourd.

\section{Materials and Method}

The economic impact assessment utilizes data from a farm-household survey and from previous on-farm experiments that compared sweet gourd production with 
and without pheromone use for managing fruit fly. A survey of 300 farmers was conducted from June to August 2006. Four survey districts: Jessore, Comilla, Chittagong, and Norsingdi were chosen because they were intensive vegetable growing areas. The survey asked about farm and household characteristics, pesticide use, and pest management practices. Knowledge and perceptions about pesticides and integrated pest management (1PM) were also recorded. In addition to the survey, integrated pest management (1PM) experts were interviewed about government regulations related to pesticides, 1PM policy, and expected future $1 \mathrm{PM}$ adoption rates in various districts, including the use of pheromones. Results of the farm-level experiments on the efficacy of pheromone traps provided data on input costs and yields.

Economic analysis to assess the total or market level benefits of pheromones was conducted using an economic surplus model in which shifts in supply and demand curves were projected based on changes in yield due to reduced pest damage, changes in input costs, and projected adoption of the technology. Changes in economic surplus that were calculated in the model were discounted and totaled over 15 years to provide estimates of economic benefits of the technology to producers and consumers. A "closed economy" specification of the economic surplus model was used since few cucurbits are traded internationally. The basic economic surplus model of research benefits is described in Alston, Norton and Pardey (1995). Their depiction of the surplus model is presented in Fig. 1, where D represents the demand for the product, and $S_{0}$ and $S_{1}$ represent supply of the product before and after a research induced technical change. The initial equilibrium price and quantity are $\mathrm{P}_{0}$ and $\mathrm{Q}_{0}$; after the supply shift they are $\mathrm{P}_{1}$ and $\mathrm{Q}_{1}$. The area beneath the demand curve and between the two supply curves $\left(\Delta \mathrm{TS}=\right.$ area $\left.\mathrm{I}_{0} a b \mathrm{I}_{1}\right)$ represents the total (annual) benefit from the research induced supply shift" (Alston, Norton and Pardey, 1995, pp. 210).

Fig. 1. Economic Surplus Measurement.

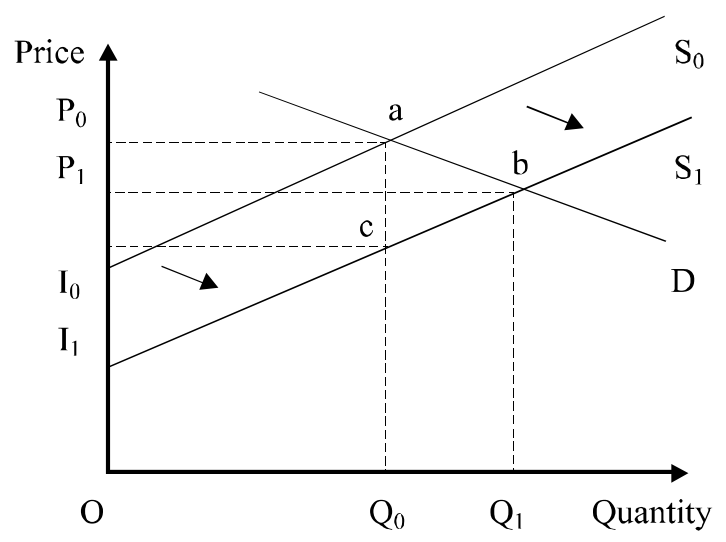

Source: Alston Norton, and Pardey (1995), p.209. 
The shift in supply from $S_{0}$ to $S_{1}$ is due to yield improvement or reduction in cost following adoption of the new technology. The benefits can be viewed as the sum: (a) the cost saving on the original quantity (the area between the two supply curves to the left of $\mathrm{Q}_{0}-$ area $\mathrm{I}_{0} a c \mathrm{I}_{1}$ ) and (b) the change in economic surplus due to the increment of production and consumption (the triangular area $a b c$, the total value of the increment to consumption-area $\mathrm{Q}_{0 \mathrm{ab}} \mathrm{Q}_{1--}$ less the total cost of the increment to production -- area $\mathrm{Q}_{0} c b \mathrm{Q}_{1}$ ). The total benefit can also be partitioned as benefits to consumers from the change in consumer surplus $(\Delta \mathrm{CS}=$ area $\left.\mathrm{P}_{0} a b \mathrm{P}_{1}\right)$ and benefits to producers from the change in producer surplus $(\Delta \mathrm{PS}=$ area $\mathrm{P}_{1} b \mathrm{I}_{1}$ - area $\mathrm{P}_{\mathrm{o}} a \mathrm{I}_{0}$ ) (Alston, Norton and Pardey, 1995).

The formula for the change in total economic surplus is:

$\Delta \mathrm{TS}=\mathrm{P}_{0} \mathrm{Q}_{0} \mathrm{~K}(1+0.5 \mathrm{Z} \eta)$ or $\Delta \mathrm{TS}=\Delta \mathrm{CS}+\Delta \mathrm{PS}$

where,

$\Delta \mathrm{CS}=\mathrm{P}_{0} \mathrm{Q}_{0} \mathrm{Z}(1+0.5 \mathrm{Z} \eta)$

$\Delta \mathrm{PS}=\mathrm{P}_{0} \mathrm{Q}_{0}(\mathrm{~K}-\mathrm{Z})(1+0.5 \mathrm{Z \eta})$,

where $\mathrm{P}_{0}$ is the pre-research price, $\mathrm{Q}_{0}$ is the pre-research quantity, $\eta$ is the elasticity of demand, and $Z=K \varepsilon /(\varepsilon+\eta)$ (Alston, Norton and Pardey, 1995). K is the proportionate shift down in the supply curve due to the technology.

$\mathrm{K}=[\mathrm{E}(\mathrm{y}) / \varepsilon-\mathrm{E}(\mathrm{c}) / 1+\mathrm{E}(\mathrm{y})] \mathrm{p} \mathrm{A}(1+\partial)$,

where $\mathrm{E}(\mathrm{y})$ is the expected yield change, $\mathrm{E}(\mathrm{c})$ is the expected cost change, $\mathrm{p}$ is the probability of research success, $\mathrm{A}$ is the technology adoption rate, and $\partial$ is the technology depreciation rate. Projecting economic surplus changes requires data on quantities produced, prices, and price elasticities of supply and demand, expected yield increases and cost changes, probability of research success, time to complete the research, adoption rates, and research depreciation. To calculate net benefits, information on research costs is also needed.

Price and quantity data for sweet gourd production in Bangladesh were obtained from the Yearbook of Agricultural Statistics of Bangladesh. The data pertain only to sweet gourd because the field experiments were carried out primarily for that crop. The effect of pheromones on yield and input costs of other cucurbits may be similar to that of sweet gourd, but impact analyses for other cucurbits were not conducted.

Yield and cost changes were obtained using data from the on-farm trials of sweet gourd conducted by BARI. Trials were conducted with mass trapping with pheromones and with pheromones and mashed sweet gourd in combination. The minimum yield change was 30 percent and the maximum 50 percent with these strategies. The probability of success of the pheromone research was 100 percent as it was successfully completed. 
Adoption was assumed to have started in 2008 and to gradually increase among sweet gourd producers and will reach 70 percent adoption by 2012 . Estimated level and timing of adoption over time was obtained by interviewing three 1PM experts in Bangladesh. The adoption rate was expressed as the percentage of the sweet gourd growing area in Bangladesh.

Demand and supply elasticities were needed as they represent the responsiveness of supply and demand to changes in price. In other words the elasticities are related to the slopes of the supply and demand curves in Fig. 1. Smaller elasticities imply steeper the curves. A demand elasticity of -.4 was assumed for sweet gourd, which implies that a one percent price reduction increases the quantity demanded of sweet gourd by only four tenths of one percent, which is reasonable given the relatively high amount of sweet gourd already consumed of this semi-staple crop. A supply elasticity of .5 was assumed, which implies that a one percent increase in price only increase the quantity supplied by a half a percent, which makes sense given the area already under sweet gourd and the 4 to 6 month growing season. Research costs (in taka) were provided by the IPM CRSP Office in BARI. They were incurred from 1999 to 2006 and totaled about 300,000 Taka. Net benefits were calculated by entering the economic surplus formula and the data into Excel spreadsheets. Benefits and costs were calculated, discounted at five percent to reflect the fact that benefits received sooner are worth more than benefits received later, and summed to obtain a net present value.

\section{Results}

Two baseline analyses were conducted as well as four additional analyses to assess the sensitivity of the results to basic assumptions. In the first baseline analysis, the model assumed a demand elasticity of - 0.4 , a supply elasticity of 0.5 , and a proportionate yield change of 0.5 (50 percent increase). The net present value of benefits minus costs was 271.6 million Taka or $\$ 4.0$ million over 15 years, and the internal rate of return (IRR) on research investment was 151 percent (Table 1).

In the second baseline scenario, other coefficients in the model were left the same except for the proportionate yield change, which was assumed to be 0.3 (30 percent increase). The net present value of benefits in this case was 184.6 million Taka or $\$ 2.7$ million, and the IRR was 140 percent.

The model was then run with a range of supply and demand elasticities and proportionate yield changes (Table 1) to assess the sensitivity of net benefits to the elasticity and yield assumptions. Estimated benefits were sensitive to a change in the supply elasticity or yield, but not to a change in the demand elasticity. For example, with a demand elasticity of- 0.6 rather than - 0.4 and 
other assumptions the same, the NPVs and IRRs were almost identical to those obtained when a demand elasticity of - 0.4 was assumed. Reducing the supply elasticity from 0.5 to 0.3 increased the NPV and IRR significantly, as did increasing the proportionate yield increase from 0.3 to 0.5 . A change in the assumed adoption rate by farmers (not shown in Table I) affected net benefits by approximately the same proportion as an equi-proportionate change in yield affected net benefits. The most conservative set of assumptions resulted in estimated net benefits of 185 million Taka ( $\$ 2.7$ million) over 15 years, while the most liberal assumptions results in net benefits of 428 million Taka ( $\$ 6.3$ million).

Table 1. Summary of pheromone benefits under alternative assumptions.

\begin{tabular}{l|c|l|l|l|l}
\hline $\begin{array}{c}\text { Demand } \\
\text { elasticity }\end{array}$ & $\begin{array}{c}\text { Supply } \\
\text { elasticity }\end{array}$ & $\begin{array}{c}\text { Proportionate } \\
\text { yield change }\end{array}$ & $\begin{array}{c}\text { Net Present } \\
\text { Value } \\
\text { (million } \\
\text { Taka) }\end{array}$ & $\begin{array}{c}\text { Net Present } \\
\text { Value } \\
\text { (million U.S. } \\
\text { dollars) }\end{array}$ & $\begin{array}{c}\text { Internal } \\
\text { Rate of } \\
\text { Return }\end{array}$ \\
\hline Baseline & \multicolumn{5}{|l}{} \\
\hline 0.4 & 0.5 & 0.5 & 272 & 4.0 & 151 \\
0.4 & 0.5 & 0.3 & 185 & 2.7 & 140 \\
\hline Sensitivity Analysis & \multicolumn{5}{l}{} \\
\hline 0.6 & 0.5 & 0.3 & 187 & 2.7 & 140 \\
0.4 & 0.3 & 0.3 & 275 & 4.0 & 151 \\
0.6 & 0.5 & 0.5 & 276 & 4.1 & 151 \\
0.4 & 0.3 & 0.5 & 428 & 6.3 & 165 \\
\hline
\end{tabular}

\section{Conclusion}

Estimated net economic benefits of using pheromones on sweet gourd to manage fruit fly infestations are from \$2.7 million USD to \$6.3 million USD over 15 years. Results are not sensitive to changes in the demand elasticity, but are sensitive to changes in the supply elasticity and yield. It is evident from our analysis that adoption of pheromone traps in place of insecticides for fruit fly management on sweet gourd generates substantial economic benefits to society. Estimated benefits would be even higher if environmental and health effects due to pesticide reduction were included. Field experiments documented that the use of pheromone traps reduced the cost of pest management in sweet gourd as well as pesticide use. Pheromone products are now available to farmers in Bangladesh on a limited basis through BARI and Safe Agriculture.

The Government of Bangladesh, on the recommendation of PTAC, has allowed a limited amount of Cuelure pheromone to be imported which is now being distributed to farmers. The opening of the pheromone market is a significant development for 1PM in Bangladesh. Since the demand for and benefits of pheromones are well documented, a consistent supply at a fair price should result in rapid adoption of the technology in Bangladesh. The sale and 
distribution is still controlled by BARC and the Department of Agricultural Extension, but recent developments may pave the way for additional deregulation and imports of pheromones into Bangladesh. Athough the effect on pheromone prices due to increased demand and imports is uncertain, the economic benefits appear to be high.

The insecticide industry in Bangladesh has been understandably slow to embrace technologies that might reduce pesticide sales, but hopefully the industry will embrace pheromones given the potential market and their health, environmental, and economic benefits to society. Attempts to commercialize pheromones have been mostly undertaken by the public sector in Bangladesh to date. With the increased demand by farmers for pheromones, hopefully the private sector will increase its involvement and promote the use of this product.

\section{Acknowledgements}

The authors would like to thank Ed Rajotte for comments and other assistance. Funding for this research was provided by USAID under Agreement No. LAG4196-G-00-5001- 00 to Virginia Tech and to BARI through the 1PM CRSP, but does not necessarily reflect the views of USAID.

\section{References}

Aiston, J. M., G.W. Norton and P.G. Pardey. 1995. "Science under Scarcity: Food Systems and Agrarian Change." Ithaca, Cornell University Press.

Bangladesh Bureau of Statistics. 2010. (Website, accessed December 22, 2010): http://www.bbs.gov.bd/WebTestApplication/userfiles/Image/Other\%20Reports/Crop _Sum_08_09.pdf?page=/PageReportLists.aspx?PARENTKEY=191

IPM CRSP. 2002-2003. Annual Highlights for Year 10 (2002-2003). (Website accessed July 15, 2009): http://www.oired.vt.edu/ipmcrsp/communications/annrepts/ highlights/HighlightsYear10.pdf

IPM CRSP. 2004. Technical Bulletin, Bangladesh Agricultural Research Institute, Gazipur, Bangladesh. 